Journal of Management

Vol. XX No. X, Month XXXX 1-26

DOI: $10.1177 / 0149206315610634$

(C) The Author(s) 2015 @ (1) @

Reprints and permissions:

sagepub.com/journalsPermissions.nav

\title{
A Multilevel Analysis of the Use of Individual Pay-for-Performance Systems
}

\author{
Paul Gooderham \\ NHH-Norwegian School of Economics \\ Mark Fenton-O'Creevy \\ Open University \\ Richard Croucher \\ Middlesex University \\ Michael Brookes \\ Newcastle University
}

\begin{abstract}
Compensation systems, such as individualized pay-for-performance (I-PFP) schemes for employees, represent an important approach to aligning employer-employee interests. However, the adoption of I-PFP is much less common in many countries than in the United States. Employing a multilevel analysis of over 4,000 firms in 26 countries, we explore determinants of its adoption. At the country level, we distinguish between cultural and institutional (labor regulation institutions) influences. At the firm level, we distinguish firms that view human resources as strategically important and firms that are foreign owned. On the one hand, our findings indicate that both cultural and institutional effects at the country level significantly influence the adoption of I-PFP. On the other hand, senior managers' agency counts. We find the effect of labor regulation on I-PFP to be mediated by its effects on labor union influence, and we find the effects of culture on I-PFP to be entirely mediated by labor regulation and (country-level) union influence.
\end{abstract}

Keywords: compensation, bonuses, and benefits; culture; institutional theory

\footnotetext{
Acknowledgments: The authors would like to acknowledge the helpful comments on previous versions of this manuscript provided by David Wilson, Patrick Wright (editor), and two anonymous reviewers. They also acknowledge the efforts and expertise of members of the CRANET network in collecting the data on which this study relied.

Corresponding author: Mark Fenton-O'Creevy, Open University Business School, Walton Hall, Milton Keynes MK7 6AA, UK.

E-mail: mark.fentonocreevy@open.ac.uk
} 
Compensation systems are critical in aligning employer-employee interests (Shaw, Gupta $\&$ Delery, 2000) and typically constitute one of the largest firm costs. Compensation approaches, including pay for performance, have been the focus of a significant body of research. However, this body of work has three important lacunae. First, as Larkin, Pierce, and Gino (2012) note, this research has tended to be dominated by a focus on executive compensation (a very small element of most firms' costs), with less attention paid to compensation for other employee groups. Second, while cross-national variation in compensation practices has received some attention, as with other human resources (HR) practices, crossnational effects may have been mischaracterized through a failure to consider the relative variance explained by country-level and firm-level factors. Thus, accounts of cross-national variation in management practice that focus primarily at the country level may be underplaying the potential role of managerial agency in bringing about between-firm variation in management practices. Third, common to cross-national research has been a virtually exclusive focus on cultural rather than institutional explanations of cross-national variation (Wright \& van de Voorde, 2009).

In this paper we address the first of these gaps through a focus on the use of individualized pay-for-performance (I-PFP) schemes for employees at both managerial and nonmanagerial levels. We address the second issue by drawing on firm-level data across multiple countries and taking a multilevel approach, thereby enabling us to specify the role of managerial agency in resisting local cultural and institutional pressures. We address the third by considering both cultural and institutional explanations of cross-national variation in I-PFP.

Our motivation for studying I-PFP stems from the economic and strategic importance of these practices and from the well-documented observation that whereas "calculative" HR practices, such as I-PFP, are prevalent in the United States, their diffusion within, for example, western European countries is significantly more limited (Gooderham, Nordhaug, \& Ringdal, 2006). However, it is unresolved as to what extent these divergences are a product of culture or institutions. Further, within countries, it has been observed that there are significant variations in firms' adoption of I-PFP (Croucher, Gooderham, \& Parry, 2006), suggesting that explanations of its adoption must take into account not only national-level but also firm-level factors. To avoid misspecification of the influence of national-level factors and to accommodate firm-level latitude requires a multilevel research approach.

In general, cross-national theorization of compensation systems is characterized by two primary approaches: the cultural and, more recently, the institutional (Xu \& Shenkar, 2002). Both predict cross-national differences in the use of compensation systems. Cultural theory has been the dominant approach in international management research. For example, Hofstede (1980b) and House, Hanges, Javidan, Dorfman, and Gupta (2004) argue that choice of compensation systems is related to national culture. As institutional theory has come to be applied, one important strand points to the significance of national institutional regimes of labor regulation for understanding organizational behavior (e.g., Campbell, 2007; Gooderham, Nordhaug, \& Ringdal, 1999; Young \& Makhija, 2014). A second strand is that of institutional actors, such as labor unions, who can influence the enforcement of labor regulation. Strict national systems of labor regulation are generally associated with strong labor unions (Hall \& Soskice, 2001) that together may limit firms in their choice of individualized compensation systems, such as I-PFP. However, it is unclear whether labor regulation and labor unions have separate impacts or if the latter mediates the former. 
Because few studies to date have combined both cultural and institutional theoretical perspectives, it is unclear whether they provide equally cogent explanations of cross-national differences in compensation systems, or whether one has significantly more explanatory power than the other, or whether they provide complementary explanations. Therefore, the first purpose of our study is to investigate the relative and combined contribution of the cultural and institutional perspectives to explaining national variations in the application of one distinctive individualized compensation system, I-PFP.

A second, related purpose of our study is to contribute to theoretical discussions of whether firms should be viewed as dominated by their environments or whether they should be seen as having considerable autonomy, so that while the environment is an influence, it does not determine their choices of management practices (Hall \& Soskice, 2001; Oliver, 1991). This is novel because as Wright and van de Voorde (2009) have indicated, prior work on crossnational variation in management practices has generally failed to consider firm-level factors. To respond to this issue, we develop an agency perspective. The agency perspective sees structuralist accounts of organizational behavior as too deterministic. Whereas institutional theorists have focused on the value of conformity with the institutional environment and the advisability of adhering to external rules and norms for firms to survive and access key resources, Oliver (1991) argues that organizations may bypass or resist local institutions when they believe it strategically important to do so.

Two main sources of firm latitude or environmental heterogeneity have been suggested. One source is captured by the concept of institutional entrepreneurship. This describes how actors, such as top managers and their organizations, are, despite institutional pressures, able to "courageously" adopt "contested" practices (Sanders \& Tuschke, 2007: 33), even bringing about change in the nature of institutions (Battilana, Leca, \& Boxenbaum, 2009). Battilana et al. (2009: 67) argue that the concept of institutional entrepreneurship challenges "the notion of individuals as over-socialized and slavishly devoted to the reproduction of habits ... and enables us to explore actors' degrees of agency, however institutionally embedded human agency might be." For example, previous research indicates that where top managers attach strategic importance to HR management issues, they will likely actively resist institutional pressures toward adopting particular employment practices (Croucher et al., 2006; Fenton-O'Creevy \& Wood, 2007). Part of this resistance may involve dealing with labor unions within the firm or at the national level that may exert pressure to refrain from adopting individualistic approaches to rewarding employees (Osterman, 2011).

A second potential source of firm-level latitude is foreign ownership. It has been argued that subsidiaries of foreign multinational corporations (MNCs) are less embedded in their host country settings than their indigenous counterparts and therefore have greater potential for agency in relation to local institutional pressures (Gooderham et al., 2006). MNC managers face conflicting institutional demands and therefore competing institutional models of action (Kostova \& Roth, 2002) that are particularly prevalent when institutionalized norms and practices conflict with day-to-day efficiency needs (Pache \& Santos, 2010).

As Heugens and Lander (2009: 77) argue, the problem facing structure-agency theorists has thus far been that testing hypotheses that include both macrolevel and organizationallevel factors "requires resources that are almost always in excess of what research teams can furnish for primary studies." Arguably, this challenge is particularly acute in research that aims to distinguish between national- and organizational-level effects. Multilevel analysis 
involving the national level, without sufficient access to a relatively large number of national settings, is unable to draw sufficiently robust conclusions. In this study, we overcome this challenge by employing data from 4,207 firms located across 26 nations to develop a multilevel analysis of the use of a specific HR management (HRM) practice: I-PFP. The framework is twofold. At the national level, we examine both institutional and cultural factors. At the firm level, we integrate managerial choice in regard to strategizing HRM as well as the effect of foreign ownership and labor union influence. In this, we respond to calls to combine factors at different levels of analysis (Wright \& van de Voorde, 2009; van Essen, Heugens, Otten, \& van Oosterhout, 2012).

In summary, by empirically examining the antecedents of compensation systems at both the national and firm levels, we are able to contribute to the structure-agency debate and those accounts of organizational behavior suggesting that managers have bounded choices. Further, we are able to specify the degree to which that boundedness should be understood as cultural or institutional in nature. Finally, in incorporating labor union influence, we are able to address the issue of whether institutions in the sense of labor regulation are dependent for their implementation on the influence of external, nonstate bodies.

\section{Theory and Hypotheses}

\section{$I-P F P$}

Pay for performance comprises merit and/or bonus pay (Nyberg, Pieper, \& Trevor, 2013), which may be a product of individual or group-based assessments and may involve individual- or group-level rewards. Our focus is on I-PFP. Sturman, Shao, and Katz (2012) observe that while employee turnover is generally more likely among both low and high performers, I-PFP helps companies retain top talent. However, they find that culture moderates the curvilinear relationship between employee performance and turnover. One implication of their research is that the implementation of I-PFP will be particularly prevalent in low-uncertainty avoidance, individualistic, and achievement-oriented cultures where high-performer turnover is most common. Additionally, Sturman et al. suggest that laws that make it more difficult to fire employees may affect the curvilinear relationship. Sturman et al. do not address the way labor unions may resist the adoption of I-PFP, given their collectivistic approach to wage bargaining (Osterman, 2011). Nor do they consider to what extent firms exercise agency and adopt I-PFP regardless of culture or institutional context.

While calculating the precise diffusion of I-PFP is problematic, Gerhart, Rynes, and Fulmer (2009) observe that merit pay based on appraisal ratings, usually by an employee's supervisors, that differentiate employees on the basis of performance is widespread in the United States, with roughly $90 \%$ of organizations employing it. One type of explanation of its prevalence in the United States involves institutional change in the 1970s, when the New Deal employment relations regime gave way to a new approach (Weinstein \& Kochan, 1995). This emphasized the need to link HR policies in general and compensation systems in particular with wider business strategies via reward and appraisal and improved methods for monitoring employee development. It differed significantly from the New Deal model: Formerly, wages were linked to jobs and employee groups, but firms now had significantly more latitude and implemented compensation systems directly linking firm strategy and individual employee behavior (Gooderham et al., 1999). Thus a key assumption in strategic 
HRM as it developed in the United States is that firms have discretion to introduce HRM practices aligned with their competitive strategies and that one core practice within the new paradigm is I-PFP (Tichy, Fombrun, \& Devanna, 1984). Recent studies by Crossland and Hambrick (2011) support the notion that managers of firms based in the United States have more leeway than their counterparts in many European countries, such as Germany, but also in relation to a range of other countries, including Japan.

The existence of firm latitude in itself does not necessarily constitute a sufficient explanation of merit pay or, more broadly, of I-PFP in the United States. A second type of explanation relates to a key finding of job turnover research that job performance and the probability of voluntary turnover follows a $U$ shape, with turnover more likely among low and high than among average performers (Trevor, Gerhart, \& Boudreau, 1997). High-performer turnover is costly for organizations in that top performers are difficult and expensive to recruit. However, when pay and performance are strongly linked, there is a significantly greater likelihood of top performers remaining (Trevor et al., 1997).

In their review of the pay-for-performance literature, Gerhart et al. (2009: 258) argue that people with higher need for achievement prefer jobs where pay is linked to performance and that "most employees (at least in the U.S.) prefer that their pay be based in individual rather than group performance." As a result, organizations use pay for performance in an attempt to address turnover and motivation. Questioning the universality of the $U$-shaped performanceturnover relationship, Sturman et al. (2012) introduce a further note of caution in regard to the adoption of I-PFP beyond the United States. They argue that most job turnover research has been carried out in the United States and that while findings indicate that the $U$-shaped performance-turnover relationship is generalizable across countries, cultural factors significantly alter this curvilinear performance-turnover relationship. Given this, one should expect that in certain contexts, organizations may decide that there is significantly less need to introduce I-PFP. More specifically, Gerhart et al. speculate that I-PFP is likely to fit better in settings where competition between individuals is encouraged and cooperation is regarded as relatively unimportant. In short, the transferability of I-PFP may be moderated by cultural factors.

The particularity of I-PFP to the United States has been documented by research indicating that it is relatively uncommon in continental Europe (Gooderham et al., 1999) and that U.S. MNCs are confronted by barriers when transferring it to their operations in continental Europe (Fenton-O'Creevy, Gooderham, \& Nordhaug, 2008; Gooderham et al., 2006). It has been argued by Taylor, Beechler, and Napier (1996) that differential transferability of HR practices arises from institutional and cultural dissimilarities. However, the issue of the relative significance of institutional or cultural explanations of I-PFP is unresolved.

Distinguishing the effects of institutions and culture has not been assisted by the cultural paradigm's dominance. Researchers have used cultural measures between countries since Hofstede's (1980a) typology was developed. In comparison, equivalent measures for the institutional environment were developed only relatively recently (Botero, Djankov, La Porta, Lopez-de-Silanes, \& Shleifer, 2004; Hall \& Gingerich, 2004) and have yet to be widely utilized. By adopting Botero et al.'s (2004) labor regulation approach in tandem with the most germane of Hofstede's dimensions of national culture (Sturman et al., 2012), we estimate the joint and relative impacts of both institutional and cultural factors on firms' deployment of I-PFP across different countries. 


\section{The Degree of Labor Regulation}

Neoinstitutional theorists "are generally skeptical of atomistic accounts of social processes, such as those provided by neoclassical economists or rational choice political scientists ... [Instead they] tend to view the source of organizational action as exogenous to organizations themselves" (Heugens \& Lander, 2009: 61). Neoinstitutional accounts of management decision making take as their starting point "the striking homogeneity of practices and arrangements" within specific "fields" (DiMaggio \& Powell, 1991: 9) and argue that institutions are "constraints on human agency" (DiMaggio \& Powell, 1991: 28) that shape firms' practices. Thus, neoinstitutional theory has often been used to explain similarity of practices between firms located in specific settings.

However, more recently, institutional perspectives have increasingly also been deployed to explain transnational diversity in the incidence of specific practices (Geppert, Matten, \& Williams, 2002). While theoretical perspectives within the institution-based view of crossnational management practice differ, they generally take as their common starting point the view that firm strategies and choice of management practices are "passive and conforming" in relation to institutional pressures (Oliver, 1991: 146). This is particularly evident in the work of Botero et al. (2004) and the role labor regulation plays in determining management practices. Botero et al. (2004: 1339) contend that "every country in the world has established a complex system of laws and institutions intended to protect the interests of workers." Further, they argue that systems of labor regulation constitute formal institutions that constrain the actions of firms, their managers, and employees through rewarding or sanctioning particular courses of behavior (see also van Essen et al., 2012).

As we note above, a key motivation to introduce I-PFP is to avoid turnover of high achievers. However, not all managers will be equally free to adopt I-PFP. Botero et al. (2004) distinguish two bodies of labor regulation with especial relevance for the adoption of I-PFP: employment law and collective relations law. Employment law regulates the individual employment contract, meaning that the more rigid the contract, the more restrictions there are on employing organizations in terms of the range of contracts they can implement and the degree to which they can differentiate pay based on likelihood of employee turnover. This constitutes one important limitation on the use of I-PFP. Collective or industrial relations laws regulate the negotiation, adoption, and enforcement of collective agreements, the activity of labor unions, and industrial action by employees and employers and are the source of a further restriction on individualized approaches to pay, such as I-PFP. Where the law specifies or supports collectively negotiated pay, this militates against I-PFP. Although neither employment law nor collective relations law has been directly applied in previous research on the adoption of I-PFP, Deakin, Lele, and Siems (2007) find that I-PFP is more likely to be encountered where labor regulation is relatively weak, such as the United States. Thus, we hypothesize the following:

Hypothesis 1: The weaker a country's labor regulation, the greater the adoption of I-PFP in that country.

One view of labor regulation is that it is prohibitive. Thus Botero et al. (2004: 1339) take the view that labor regulation "governs" management practices. However, Oliver (1991) suggests that managers are able to exercise strategic agency and to bypass or resist regulatory 
pressures. If labor regulation influences rather than determines the adoption of I-PFP, we might therefore expect significant diversity in its adoption even in countries where the local regulatory environment is not conducive to such practices. Thus, if strategic agency can overcome local institutional constraints, we should expect to see examples of both high and low adoption of I-PFP in all countries. Hence, we predict the following:

Hypothesis 2: Regardless of the degree of labor regulation, there will be examples in each country both of firms adopting high levels of I-PFP and of firms with low adoption of I-PFP.

\section{Culture}

We have documented that I-PFP use grew substantially in the United States in the early 1980s (Tichy et al., 1984). One likely factor constraining its adoption by firms in other countries is the institutional environment in terms of dissimilarities in labor regulation. Another potential factor is culture, referring to the commonly held body of beliefs and values shared by members of a particular group that distinguishes them from other groups. For Hofstede, culture is "the collective programming of the mind that distinguishes one group or category of people from another" (Hofstede, 1993: 89). It is the product of long-term historical processes and is relatively stable over time. Culture contrasts therefore with institutions, which arise from more recently negotiated legal frameworks and social and economic structures and which are more subject to change (Hall \& Soskice, 2001).

Culture is viewed as an important predictor of variation in managerial behavior between national contexts (Tsui, Nifadkar, \& Ou, 2007: 430). Firms operating in similar cultures will develop similar notions as to which compensation systems are suitably motivating; conversely, firms operating in different cultures will develop very different notions. As we argued above, while the $U$-shaped performance-turnover relationship has been documented for the United States, its universality has been questioned by Gerhart et al. (2009), who view it as more likely to hold in societies where competition between individuals is accepted. Thus in terms of Hofstede's (1980a) cultural dimensions, the pronounced incidence of I-PFP in the United States could be ascribed to its position on the Individualism/Collectivism dimension. This dimension plots the degree of preference for a loosely knit social framework in which individuals are expected to take care of only themselves and their immediate families as opposed to a preference for a tightly knit social framework in which individuals can expect their relatives or members of a particular in-group to look after them in exchange for loyalty. A society's position on this dimension is reflected in whether people's self-image is defined in terms of "I" or "we." Thus Hofstede argues that for the United States, the most individualist country in Hofstede's set of 79 countries and regions (Hofstede, Hofstede, \& Minkov, 2010), "the Individualist conception [means that] the relationship between the individual and the organization is essentially calculative, being based on enlightened self-interest" (Hofstede, 1980b: 61).

The significance of individualism/collectivism in regard to the distribution of rewards has been observed by several researchers who find that in collectivist societies, there is a preference for rewards to be distributed equally among group members rather than to be individually targeted (Hui, Triandis, \& Yee, 1991). In individualistic cultures, on the other hand, I-PFP appeals directly to the "utilitarian involvement" aspect of individualism that stresses and links individual responsibility with recognition (Smith, Dugan, \& Trompenaars, 1996). 
Hence, concerning I-PFP, Schuler and Rogovsky (1998: 172) found "that individual incentive compensation practices have a better fit in countries with higher levels of Individualism."

Thus, we propose the following at the national level:

Hypothesis 3a: The greater the degree of individualism, the greater the adoption of I-PFP.

Societies characterized by low tolerance of uncertain situations and career instability may also be significantly less inclined to introduce contingent compensation systems. Instead there will be a preference in societies with high degrees of the Uncertainty Avoidance dimension (Hofstede, 1980a) for compensation systems with more predictable earnings. Schuler and Rogovsky's (1998) cross-national research indicates that in addition to individualism being significantly correlated with firms' use of I-PFP, firms in countries with high levels of uncertainty avoidance are markedly less inclined to use these practices. Thus, we further propose the following:

Hypothesis $3 b$ : The lower the degree of uncertainty avoidance, the greater the adoption of I-PFP.

Of Hofstede's (1980a) other cultural dimensions, the Masculinity/Femininity dimension, sometimes referred to as "performance orientation" (Hofstede et al., 2010), is clearly relevant for an analysis of the impact of culture on I-PFP. "Masculinity denotes a preference in society for achievement, heroism, assertiveness and material rewards for success. Society at large is more competitive. Its opposite, femininity, stands for a preference for cooperation, modesty, caring for the weak and quality of life" (Hofstede Center, 2014). Thus, in countries with masculine cultures, there will be a preference for being materially rewarded according to one's own individual attainments. In feminine societies, the opposite applies. Indeed, "Individual brilliance in a Feminine society is suspect" (Hofstede, 1983: 85). Thus in masculine societies, the $U$-shaped performance-turnover relationship will be particularly pertinent. Therefore, we hypothesize the following at the national level:

Hypothesis $3 c$ : The greater the degree of masculinity, the greater the adoption of I-PFP.

Common to our institutional and cultural hypotheses is the assumption that the adoption of I-PFP by firms is a response to their national contexts. However, these two theories conceive the underlying decision-making mechanism very differently. The institutional explanation assumes that I-PFP is a motivational practice that is equally effective across firms but that its implementation is subject to institutional restriction. The cultural explanation is based on a different assumption. It views I-PFP adoption as a reaction to the probability of high-performer turnover. In collectivistic, high-uncertainty avoidance, and feminine cultures, this probability is lower, and therefore firms are less likely to adopt I-PFP. Additionally, the cultural perspective would argue that in those cultures where I-PFP breaches collective norms, it will be avoided.

In terms of the relationship between culture and institutions, one view is that institutions are not the direct "result" of national culture but arise from specific historic settlements between different interest groups that are constantly renegotiated across time (Hall \& Thelen, 2009). However, many other scholars view culture and institutions as significantly connected (Alesina \& Giuliano, 2013). One view is that culture and institutions interact and that this makes determining causality problematic (Alesina, Algan, Cahuc, \& Giuliano, 2015). However, Hofstede's (1980a: 27) view is that institutions are "consequences" of national 
culture and mediate its impact on organizational practice. Although it remains problematic to determine causality or coevolution as the more appropriate view of the relationship between culture and institutions (Alesina \& Giuliano, 2013), Sakamoto, Woo, Takei, and Murase (2012) argue in a study of rising inequalities in pay in the United States compared to Japan that while culture directly influences the degree to which individualistic approaches to pay are adopted, it also exerts an indirect effect through preferences for labor market institutions, such as particular forms of employment protection legislation. Thus, for example, we might expect more individualistic- or achievement-oriented societies to be less inclined to enact regulations that support collective representation or place limits on management autonomy. Given this, we explore Hofstede's proposition that institutions mediate the impact of culture and hypothesize the following:

Hypothesis $3 d$ : The effect of culture on I-PFP is mediated by the degree of labor regulation.

We now discuss the impact of firm-level influences on the adoption of I-PFP. We first distinguish two key managerial agency influences on I-PFP adoption: the strategic importance accorded to HRM and the influence of ownership. We then consider the role of labor unions in influencing I-PFP adoption and in mediating the effects of labor regulation.

\section{Strategic Importance of HRM}

We argue that the adoption by firms of I-PFP is dependent on the degree to which top management accords strategic importance to HRM. As Sheehan (2005) argues, the integration of strategy and HRM will be most readily achieved when HR managers are integrated into the strategy process. This is critical for the application of I-PFP, which involves consistently aligning employee compensation with the realization of the firm's strategy. One tangible indication that top managers believe HRM to be strategically important is that the HR department is involved in strategy development.

Firms in which HR departments are allotted a strategic role are distinctive from those whose HR departments have no input into firm-level strategy and where HR decision making may be devolved to line managers. Without a strategic role for HR, immediate operational concerns dominate and I-PFP is unlikely to be practiced with any regularity (Larkin et al., 2012; McGovern, Gratton, Hope-Hailey, Stiles, \& Truss, 1997). According strategic importance to HRM may mean managers see HR practices as sufficiently important to bypass local institutions when they conflict with efficiency considerations. Oliver (1991) argues that managers, when motivated, are able to resist or bypass local institutional constraints. FentonO'Creevy and Wood (2007) provide evidence that institutional pressures on HRM practices may have less impact where senior managers believe HRM to have strategic importance. We therefore hypothesize the following:

Hypothesis 4: Firms that accord strategic importance to HRM are more likely to adopt I-PFP.

\section{Ownership}

Kostova and Roth (2002: 215) argue that "a central tenet of the institutional perspective is that organizations sharing the same environment will employ similar practices and thus become 'isomorphic' with each other." In terms of the institutional perspective, there are, 
within each country, distinctive local pressures that firms respond to in order to achieve legitimacy (DiMaggio \& Powell, 1983) and that result in the adoption of similar practices, leading to country-specific practices. The cultural perspective is also one of distinct country differences in managerial practices (Hofstede, 1980b).

However, Kostova and Roth (2002) further argue that MNCs will attempt to leverage their nationally conditioned practices on a worldwide basis because MNCs will view them as core to their organizational capabilities and therefore as an important source of competitive advantage. Others argue for the importance of organizational imprinting as a mechanism for country-of-origin effects (e.g., Johnson, 2007) or ascribe a key role to expatriate managers (Björkman, Budhwar, Smale, \& Sumelius, 2008). Thus, while the management practices of MNCs may be subject to some degree of local adaptation, we should also observe a countryof-origin effect that not only distinguishes subsidiaries of MNCs from domestically owned organizations but distinguishes subsidiaries according to country of origin. Prior studies have found country-of-origin effects on local HRM practices. For example, Gooderham et al. (2006) find that subsidiaries of U.S. MNCs in the United Kingdom, Ireland, Denmark, Norway, and Germany have HR practices that diverge systematically from those of domestic firms. Beck, Kabst, and Walgenbach (2009) find a country-of-origin effect for the extent of continuing vocational training. However, it is unclear whether studies that identify a countryof-origin effect have identified an effect due to the country of origin or one that is associated simply with foreign ownership. The latter effect might occur due to a convergence to a common global standard or greater encouragement for managers to question local practices. Thus in testing for a country-of-origin effect, it is important to distinguish between a foreign ownership effect and an effect in which the country of origin matters.

We therefore hypothesize the following:

Hypothesis 5: Variation in the country of origin of firms will be associated with significant variance in their adoption of I-PFP over and above the variance associated with domestic versus foreign ownership.

\section{Labor Union Influence}

In most European and some non-European countries, employee representatives have a legally established role. This governance mandate is institutionalized through law. While firms may attempt to circumvent these legal requirements (Bormann, 2007), I-PFP may be difficult or impossible to apply where unions have an active presence. Typically, labor union wage policies within and across firms have an egalitarian focus, which leads to significant resistance to individualized performance-related pay approaches, compressing the wage structure (Metcalf, Hansen, \& Charlwood, 2001). Even in the quite different case of the countries of the former Soviet Union, coercive influences by labor unions on employers may be present within individual firms. Thus, it has been shown that enterprise-level unions in these countries are capable, under specific circumstances, of challenging the operation of individual pay schemes (Morrison, Croucher, \& Cretu, 2012). In the case of liberal market economies, such as the United States (Hall \& Soskice, 2001), organized labor in parts of the manufacturing industry, such as automobile manufacture, may also exercise similar pressure (Katz, 1997). Thus, labor unions may constrain the adoption of I-PFP. 
Hypothesis 6a: Labor union influence will be inversely associated with the adoption of I-PFP.

However, the influence of labor unions is not confined to the individual firm level. As collective bodies operating at the national level, labor unions are likely to resist any tendencies by firms in general to introduce the individualization of remuneration that is at the core of I-PFP. They will seek to influence firms through two principal channels. The first of these involves ensuring that laws and regulations that limit or challenge I-PFP as a management practice are clearly visible. The second involves actively monitoring for deviations from laws and regulations and, if necessary, employing coercive power to compel firms to conform to the country's labor regulations (Osterman, 2011). Higher levels of labor regulation and of regulation supporting collective institutions strengthen the societal influence of labor unions since they increase their coercive power. This implies that labor unions will be an important mechanism through which labor regulation institutions are enacted and that labor union influence mediates the effect of labor regulation on the adoption of I-PFP. Thus we hypothesize the following:

Hypothesis 6b: Labor union influence will mediate the inverse relationship between the strength of a country's labor regulation and the adoption of I-PFP by firms.

\section{Method}

\section{Data and Sample}

We use data drawn from a cross-national firm-level survey of HRM conducted by the Cranfield Network on International Human Resource Management (CRANET). CRANET comprises a network of HR researchers located at business schools in over 20 countries. In 1994, it developed a common questionnaire administered at approximately five yearly intervals. The data we employ is from the most recent round of data collection in 2009-2010. The questionnaire was mailed to the most senior HR manager in nationally representative samples of companies with more than 100 employees. In other words, all sectors were sampled and the unit of analysis is the company.

CRANET has addressed potential comparability issues by intensive collaboration between researchers in the various relevant countries (Brewster, Tregaskis, Hegewisch, \& Mayne, 1996; Parry, Stavrou, \& Lazarova, 2013). Ensuring appropriate translation into the various languages in these countries "required many meetings of members and the use of practitioner panels to help to provide a reality check on the outcomes" (Lazarova, Morley, \& Tyson, 2012: 4). Answers from the first 10\% were compared to those from the last $10 \%$ of respondents, and no evidence of systematic response bias was identified.

"The questions asked were deliberately designed to rely on factual information about HRM at the organizational level. . . . Furthermore, to discourage 'guessing', respondents were advised to leave blank any questions for which they did not know the answer" (Parry et al., 2013: 4). While response rates are low (generally 12\% to 25\%), Brewster, Hegewisch, Mayne, and Tregaskis (1994) showed that CRANET's approach gave proportionate sector and industry representation and concluded that the survey's statistical representativeness is satisfactory. 
The complete data set encompasses 6,258 firms. Removing the countries omitted from any of the cultural and institutional indices discussed below reduced the set to 4,397 firms. Removing noncommercial governmental and public service organizations meant that usable data on 4,207 firms across 26 countries were available. As with most large surveys, many variables in the CRANET data set have some missing values. In particular, the variable "strategic importance of HRM" has 13\% missing data and the variable "labor union influence" has around 9\% missing data. In line with good practice (Allison, 2001), we used a multiple imputation approach to address missing values, which uses data efficiently but adjusts standard errors for the error of imputation. We used the Markov chain Monte Carlo method in SPSS to impute 10 different versions of the data set. Also in line with good practice, we included all variables occurring in our model as a basis for estimating missing values and included additional variables from the wider data set that showed strong correlations with the variables with missing values. Including the wider set of variables reduces error of imputation (Allison, 2001). All results reported are pooled, based on analyses conducted using multiple imputation of missing values, with standard errors and significance adjusted for the error of imputation.

Table 1 gives sample size for each country and country means for I-PFP.

\section{Measures: Independent and Dependent Variables}

Dependent variable: I-PFP. The (firm-level) dependent variable, the implementation of I-PFP, is created from responses to nine questions on the use of individualized performance measurement and reward systems. These ask, "Do you have formal performance appraisals?" for each of managers, professionals, clerical staff, and manual workers; "Do you make use of performance-related pay?" for each of managers, professionals, clerical staff, and manual workers; and "Do you use appraisal data to inform pay decisions?" The responses to these nine questions are all dichotomous, that is, yes or no, and the responses are used to create a Mokken scale reflecting the individual firm's commitment to I-PFP. This scale models I-PFP as a latent variable, which is assumed to be measured by the nine dichotomous items with error. The scale has acceptable reliability (Cronbach's alpha $=.87$ ) and scalability coefficients $(\mathrm{H}$-value $=.48)$. It thus exceeds the minimum recommended criteria for reliability $(>.70)$ and scalability (>.30) proposed by Sijtsma and Molenaar (2002). Thus, it is valid to aggregate the nine items into a single scale representing level of I-PFP adoption.

Labor regulation. In order to operationalize labor regulation, we have combined Botero et al.'s (2004) indices of employment law and collective relations law, taking the mean score on the two indices and rescaling from 0 to 100 (for consistency with the measurement scale we use for culture). The index of employment laws reflects the "incremental cost to the employer of deviating from a hypothetical rigid contract, in which the conditions of a job are specified and [an employee] cannot be fired" (Botero et al., 2004: 1353). Collective relations laws protect employees from employers by permitting collective action.

Culture. Culture is operationalized using Hofstede's dimensions of Individualism, Uncertainty Avoidance, and Masculinity (Hofstede et al., 2010).

Strategic importance of HRM. The extent of the strategic importance top management accords to HR management is operationalized using data recording the point at which the 
Table 1

Sample and individualized Pay-For-Performance (I-PFP) Values by Country

\begin{tabular}{|c|c|c|}
\hline Country & $n$ & Mean Country I-PFP \\
\hline Sweden & 192 & 3.40 \\
\hline Denmark & 306 & 3.71 \\
\hline Lithuania & 112 & 3.97 \\
\hline Netherlands & 104 & 4.50 \\
\hline France & 156 & 4.58 \\
\hline Norway & 57 & 4.62 \\
\hline Hungary & 113 & 4.85 \\
\hline Finland & 60 & 4.86 \\
\hline Bulgaria & 240 & 4.93 \\
\hline Austria & 170 & 5.11 \\
\hline Russia & 54 & 5.30 \\
\hline Turkish Cypriot Community & 55 & 5.59 \\
\hline Japan & 385 & 5.84 \\
\hline United Kingdom & 170 & 5.96 \\
\hline Greece & 208 & 6.09 \\
\hline Israel & 52 & 6.10 \\
\hline Germany & 387 & 6.25 \\
\hline Australia & 106 & 6.25 \\
\hline Slovakia & 211 & 6.32 \\
\hline Ireland & 101 & 6.49 \\
\hline Taiwan & 226 & 6.94 \\
\hline South Africa & 132 & 7.02 \\
\hline Slovenia & 174 & 7.13 \\
\hline Philippines & 33 & 7.34 \\
\hline Switzerland & 88 & 7.67 \\
\hline USA & 315 & 7.83 \\
\hline Total & 4,207 & 5.75 \\
\hline
\end{tabular}

Note: Ordered by country mean of I-PFP.

HR function becomes involved in determining the firm's strategy. The responses are on a 4-point scale with the following options: "not consulted," "after implementation," "prior to implementation," and "from the outset."

Ownership. Since organizations may through their ownership be subject to influence and control from beyond their national setting, we consider country-of-origin effects. We do so by employing a country-of-origin variable. In terms of foreign ownership, country of origin spans 50 different countries. In conjunction with Hypothesis 5, we use individual country of origin to cross-classify firms with host country, allowing us to partition variance in firm adoption of I-PFP between home and host country. We also create a binary variable to distinguish foreign- and domestic-owned firms.

Labor union influence. Respondents are asked to rank the extent of influence labor unions have on the organization from $1=$ no influence to $5=$ a very great extent. We chose this approach in preference to a union membership measure for two reasons. First, the relationship 
between union power or influence and membership levels varies markedly between national regimes. Second, in some countries it is illegal for employers to record union membership, thus rendering such measures liable to significant levels of unreliable or missing data that vary systematically by country.

\section{Measures: Control Variables}

Size. Size is operationalized as the natural log of the total number of employees. Logs are taken to avoid any potential disproportionate influence from a few very large firms and to normalize the variable's distribution.

Public/private. While we exclude all organizations with purely governmental or public service functions, some countries have significant numbers of firms under public ownership. We distinguish between public- and private-sector organizations by including a dummy variable for public-sector employers.

Industrial sector. To control for the possibility of typical modes of production and organization in different industries being more or less conducive to using I-PFP, we include a set of industry dummies. These identify organizations operating in the primary, secondary, and tertiary sectors and include financial services as a distinct category. There is also a fifth category, labeled other, capturing those organizations combining elements of manufacturing and services that do not fit directly into any of the other categories. Secondary sector is the reference group in the analysis.

National context. In order to augment context at the country level, we include in our analysis 2010 figures for GDP per capita, in current US\$ (World Bank, 2015), and stock of foreign direct investment (United Nations Conference on Trade and Development, 2015). In the case of GDP per capita, we take the log before entering the variable into the analysis. Both are contemporaneous with the CRANET survey. Additionally, for completeness in regard to Hofstede's four main dimensions of culture, we include the dimension Power Distance.

\section{Analysis}

We have argued that a firm's decisions in regard to compensation systems are determined by firm- and country-level factors. Ownership, labor union influence, and strategic importance of the HR function are at firm level. However, labor regulation and culture act at country level on all firms. Using single-level regression analysis approaches would lead to misestimating parameters and standard errors, since independence assumptions are violated (Raudenbush \& Bryk, 2002). We therefore adopted a multilevel modeling approach using the mixed models procedure in SPSS.

The multilevel model applied here estimates the use of I-PFP as a function, simultaneously, of variables at both the firm and country levels. Labor regulation and the culture variables constitute Level 2 (country), with the remainder being entered at Level 1 (firm). Initially, all Level 1 variables (other than dichotomous variables) are entered as grand-mean centered. 
Table 2

\section{Country-Level Pearson Correlations}

\begin{tabular}{lccccccc}
\hline Variable & 1 & 2 & 3 & 4 & 5 & 6 & 7 \\
\hline 1. Labor regulation & & & & & & & \\
2. Individualism & -.18 & & & & & & \\
3. Masculinity & $-.44^{*}$ & .03 & & & & & \\
4. Uncertainty avoidance & .19 & $-.57^{* *}$ & .11 & & & & \\
5. Power distance & .33 & $-.56^{* *}$ & .21 & .37 & & & \\
6. Ln(per capita GDP) & -.14 & $.47^{*}$ & -.18 & -.14 & $-.60^{* *}$ & & \\
7. FDI stock as \% of GDP & -.01 & .30 & .00 & -.35 & -.20 & .11 & \\
8. I-PFP country mean & $-.47^{*}$ & -.19 & $.55^{* *}$ & .08 & .25 & -.10 & -.07 \\
\hline
\end{tabular}

Note: $N=26 . \mathrm{FDI}=$ foreign direct investment; I-PFP $=$ individualized pay for performance.

$* p<.05$.

$* * p<.01$.

However, while grand-mean rather than group-mean centering is appropriate for testing our primary country-level hypotheses, it is inappropriate for testing whether labor union influence mediates the effect of the strength of a country's labor regulation on I-PFP (i.e., Hypothesis 6b). Such mediation must necessarily take place via the between-country component of the union influence variable. In these circumstances, grand-mean centring can lead to biased estimates of mediation effects (Kehoe \& Wright, 2013; Zhang, Zyphur, \& Preacher, 2009). Because the independent variable in the mediation hypothesis is at country level, it can account only for country-level variance in the mediator. Hence, a test of the mediation hypothesis should focus on the between-country mediation effect (while controlling for the within-country component of the mediator to ensure precision of estimates). Thus, to test Hypothesis $6 \mathrm{~b}$, we use group-mean centering for labor union influence and enter its country mean as a Level 2 variable. In this way, we are able to partition within-country firm-level variance in union influence from between-country variation.

\section{Results}

Tables 2 and 3 display the correlations between, respectively, country-level and firm-level variables.

Table 4 shows results from estimating six multilevel models of I-PFP use. Model 1 enters all firm level variables. Models 2, 3, 4, and 5 enter labor regulation, individualism, masculinity, and uncertainty avoidance, respectively, with firm-level variables. Model 6 examines the joint effect of labor regulation and masculinity with the firm-level variables on I-PFP use (individualism and uncertainty avoidance are dropped at this stage as they showed no significant effect when entered alone).

Examining the base, intercept-only model (not shown) enables us to partition the variance in I-PFP between firm and country level. The intraclass correlation is .19, suggesting $19 \%$ of variation in firm adoption of I-PFP is accounted for by between-country differences. From Model 1, we observe that firm-level variables account for around 5\% of variance in firmlevel variation in I-PFP use and around $14 \%$ of variance in between-country differences. This suggests that $14 \%$ of cross-national variability in I-PFP adoption is accounted for by 
Table 3

Firm-Level (Level 1) Pearson Correlations

\begin{tabular}{|c|c|c|c|c|c|c|c|c|c|c|}
\hline Variable & 1 & 2 & 3 & 4 & 5 & 6 & 7 & 8 & 9 & 10 \\
\hline \multicolumn{11}{|l|}{ 1. Ln(no. employees) } \\
\hline 2. Public sector & $.05^{*}$ & & & & & & & & & \\
\hline 3. Primary sector & .01 & $.16^{* * *}$ & & & & & & & & \\
\hline 4. Tertiary sector & -.01 & -.03 & $-.20 * * *$ & & & & & & & \\
\hline 5. Financial services & $.06 * * *$ & .01 & $-.11 * * *$ & $-.23 * * *$ & & & & & & \\
\hline $\begin{array}{l}\text { 6. Other industry } \\
\text { sector }\end{array}$ & $-.06^{* * *}$ & $-.08 * * *$ & $-.12 * * *$ & $-.24 * * *$ & $-.14 * * *$ & & & & & \\
\hline $\begin{array}{l}\text { 7. Domestic-owned } \\
\text { firm }\end{array}$ & $.03 *$ & $.09 * * *$ & .01 & $.04 * *$ & -.01 & .00 & & & & \\
\hline $\begin{array}{l}\text { 8. Labor union } \\
\text { influence }\end{array}$ & $.24 * * *$ & $.15^{* * *}$ & $.12 * * *$ & -.02 & $-.11^{* * *}$ & $-.09 * * *$ & $.04 * *$ & & & \\
\hline $\begin{array}{l}\text { 9. Strategic importance } \\
\text { of HRM }\end{array}$ & $.07 * * *$ & .02 & -.01 & .02 & .00 & .00 & .01 & $.14 * * *$ & & \\
\hline 10. I-PFP & $.16^{* * *}$ & -.02 & -.02 & $-.07 * * *$ & $.08^{* * *}$ & .02 & $-.16^{* * *}$ & $-.11 * * *$ & $.05^{* * *}$ & \\
\hline
\end{tabular}

Note: $N=4,207$. Correlations computed using multiple imputation. HRM = human resources management; $\mathrm{I}-\mathrm{PFP}=$ individualized pay for performance.

${ }^{*} p<.05$.

$* * p<.01$.

$* * * p<.001$.

differences in the nature of firm populations between countries. In particular, there are sizable cross-national differences in average firm size and proportion of firms in foreign ownership, and both have a significant association with adoption of I-PFP.

\section{Control Variables}

Firm size shows a significant positive association with I-PFP; larger firms have higher average levels of I-PFP use. Public-sector firms show lower use of I-PFP. Tertiary-sector firms show lower use of I-PFP than the secondary-sector reference group, and financial services firms show greater use of I-PFP than the reference group. In our initial regression analyses, none of the country-level control variables showed a significant association with I-PFP $(\ln [\mathrm{GDP}$ per capita], $B=-.27, t=-.73, p=.465$; stock of foreign direct investment, $B=-.00, t=-.48$, $p=.631$; and power distance, $B=.01, t=1.39, p=.163$ ). Thus to avoid significant reduction in Level 2 degrees of freedom, these were dropped from further analysis and are not shown in the regression analysis tables (full details are available from the corresponding author).

\section{Independent Variables: Country Level}

Hypothesis 1 is supported. Labor regulation shows a significant inverse association with I-PFP adoption (Model 2); the coefficient for labor regulation is negative and significant, including when controlling for masculinity (Model 6).

Our arguments for the impact of institutional differences rest on two possible mechanisms. In the first, institutions are a constraint on management autonomy: Regulatory 





prohibition makes I-PFP difficult or impossible for firms to implement in some countries. Alternatively, although institutions, in the sense of labor regulation, influence managers, they do not completely constrain them, since firms are able to exercise strategic agency, resisting or circumventing local institutions when sufficiently motivated (Fenton-O'Creevy \& Wood, 2007; Oliver, 1991).

According to Hypothesis 2, we would expect to see examples of high I-PFP adoption even in countries with high levels of labor regulation. To test Hypothesis 2, we examined the distribution of uptake of I-PFP in each country and found a wide range of I-PFP values in each country. Within all sampled countries (with the exception of Japan, range 0-7, $n=385$; and Russia, range $0-8, n=54$ ) there were examples of firms scoring at both the top (9) and bottom $(0)$ of the scale. In particular, we find this to be the case in our samples of firms in both Germany and the United States (countries regarded as polar opposites in terms of "varieties of capitalism"; Hall \& Soskice, 2001). A closer examination of the Russian and Japanese cases shows that all of the nine practices in the I-PFP scale occur in firms in these countries (although no single firm in this subsample reports using all of them together).

If institutions constrain management autonomy, we would expect levels of I-PFP adoption to be low and show low variance in countries with high labor regulation but to show much greater variation of I-PFP in countries with low labor regulation, since greater management autonomy will result in a much wider variety of practice.

If institutions merely influence management behavior, and strategic agency leads to the bypassing of local institutions, while we would expect to see country-level differences in mean levels of I-PFP adoption relating to labor regulation, we would not expect differences in labor regulation to be associated with country differences in variance of I-PFP. Thus as a further test of this hypothesis we took the (population-estimated) standard deviation of the I-PFP variable and regressed it on labor regulation (controlling for culture variables). The association is nonsignificant $(.003, p=.643)$, the control variables have nonsignificant parameters, and the overall regression has a nonsignificant $F$ statistic.

Thus, Hypothesis 2 is supported, meaning that while institutions, as measured by labor regulation, influence, they do not govern managerial choice. In short, we observe a case of inhibition or influence rather than prohibition or constraint.

In terms of culture, individualism (Model 3), uncertainty avoidance (Model 5), and the control variable, power distance, do not show a significant association with I-PFP. Thus, Hypotheses $3 \mathrm{a}$ and $3 \mathrm{~b}$ are not supported. Masculinity (Model 4) does show a significant association with I-PFP; the coefficient for masculinity in Model 4 is significant and positive. Thus, Hypothesis $3 \mathrm{c}$ is supported.

We observe in Model 6 that when labor regulation and masculinity are entered simultaneously, both regression coefficients are reduced, although both remain significant, consistent with a mediation effect. We carried out a further analysis (at Level 2) testing for this mediation effect with masculinity hypothesized (Hypothesis 3d) to affect (mean country) I-PFP indirectly via labor regulation. We used the Hayes (2008) PROCESS macro for SPSS to carry out a bootstrapping procedure to conduct this test. The total effect of masculinity on I-PFP is positive and significant with a similar coefficient size to the multilevel analysis $(0.02, p=$ .003 ). The direct and indirect effects of masculinity are both significant at $p<.05$, suggesting the effects of masculinity to be partially mediated by employment regulation (indirect effect $\left.\kappa^{2}=.13, R^{2}=.15\right)$. These results provide support for Hypothesis $3 \mathrm{~d}$. 


\section{Independent Variables: Firm Level}

The regression parameter for strategic importance of HRM is positive and significant (all models): Firms that accord greater strategic importance to HRM show greater propensity to adopt I-PFP. Hypothesis 4 is supported. We conducted a supplementary analysis using groupmean centering and entered the country mean of strategic importance of HRM to examine whether this effect was primarily within or between countries. The regression parameter for the group-mean centered variable remained significant $(.19, p=.000)$, but the country mean variable parameter was nonsignificant, suggesting the effect of this variable on I-PFP to be at the within-country, firm level.

Turning to the effect of firm ownership, we conducted an analysis to investigate whether we could detect any country-of-origin effect. We examined a cross-classified multilevel model predicting I-PFP with firms clustered by both host country (firm location) and home country (of parent). In the null model, there were significant levels $(7 \%, p<.05)$ of variance in I-PFP at the home country level, consistent with a country-of-origin effect. However, controlling for domestic- versus foreign-owned status results in the unexplained variance of I-PFP between home countries becoming insignificant $(p=.082)$, failing to support Hypothesis 5. Thus within the limits of $(p<.05)$ significance, the country-of-origin effect is accounted for by whether the firm has foreign ownership. Home country explains no further variance. In short, we find an effect for foreign ownership but no specific country-of-origin effect.

When entered in grand-mean centered form (Models 1 through 6), labor union influence does not show a significant association with I-PFP. However, when partitioned into a withincountry and a between-country component (Model 7, Table 5), the country mean of labor union influence shows a significant inverse association with I-PFP, offering partial support for Hypothesis 6a.

Hypothesis $6 \mathrm{~b}$ proposed labor union influence will mediate the inverse relationship between labor regulation and I-PFP. To test this hypothesis, we followed the CWCM (centered within context mediation) variant (Zhang et al., 2009) of the Baron and Kenny (1986) approach. This requires the Level 1 mediator variable to be group-mean centered and the group mean to be used in the analysis as the mediator variable while controlling for the within-country group-centered component. Then if (a) the causal variable (labor regulation) has a significant coefficient when the mediator is not included in the equation, (b) the causal variable has a nonsignificant coefficient after controlling for the mediator, and (c) the mediator variable predicts the dependent variable, then full mediation exists.

Table 5 shows the analyses to test mediation by labor union influence of the relationship between labor regulation and I-PFP. Model 8 shows a significant association of labor regulation with I-PFP when not controlling for country mean of labor union influence (a). Entering labor union influence into the regression (Model 9) leaves the coefficient for labor regulation nonsignificant (b). A further regression (not shown) of union influence country mean on labor regulation shows a significant association $(B=.02, p=.015)$ (c). A Sobel test (Sobel statistic $=12.09, p=.036)$ confirmed that the reduction in coefficient is significant. Together, these imply that union influence mediates the association between labor regulation and I-PFP. Thus we find support for Hypothesis $6 \mathrm{~b}$.

Since we have shown both a mediation by labor regulation of the association of masculinity with I-PFP and a mediation by union influence of the association of labor regulation with 
Table 5

Testing Mediation

\begin{tabular}{|c|c|c|c|}
\hline & Model 7 & Model 8 & Model 9 \\
\hline Parameter & $B(t)$ & $B(t)$ & $B(t)$ \\
\hline Intercept & $7.21(16.77)^{* * *}$ & $7.99(9.93)^{* * *}$ & $8.11(11.08)^{* * *}$ \\
\hline $\operatorname{Ln}\left(\right.$ no. employees) ${ }^{\mathrm{a}}$ & $.29(10.78)^{* * *}$ & $.29(10.71)^{* * *}$ & $.29(10.77)^{* * *}$ \\
\hline Public sector & $-.42(-2.07)^{*}$ & $-.43(-2.11)^{*}$ & $-.42(-2.08)^{*}$ \\
\hline Primary sector ${ }^{\mathrm{b}}$ & $-.10(-.68)$ & $-.10(-.67)$ & $-.10(-.67)$ \\
\hline Tertiary sector ${ }^{\mathrm{b}}$ & $-.26(-2.63)^{* *}$ & $-.25(-2.59)^{* *}$ & $-.25(-2.62)^{* *}$ \\
\hline Financial services ${ }^{b}$ & $.33(2.64)^{* *}$ & $.33(2.43)^{*}$ & $.33(2.42)^{*}$ \\
\hline Other sector ${ }^{\mathrm{b}}$ & $.10(.75)$ & $.10(.76)$ & $.10(.76)$ \\
\hline Domestic owned & $-.79(-6.75)^{* * *}$ & $-.79(-6.77)^{* * *}$ & $-.79(-6.75)^{* * *}$ \\
\hline Labor union influence, $\mathrm{d}$ & $-.06(-1.53)$ & $-.06(-1.49)$ & $-.06(-1.52)$ \\
\hline Strategic importance of $\mathrm{HRM}^{\mathrm{a}, \mathrm{d}}$ & $.19(4.55)^{* * *}$ & $.19(4.49)^{* * *}$ & $.19(4.54)^{* * *}$ \\
\hline Labor union influence (country mean) ${ }^{\mathrm{d}}$ & $-1.19(-3.58)^{* * *}$ & & $-.93(-2.54)^{* *}$ \\
\hline Labor regulation $^{\mathrm{d}}$ & & $-.04(-2.75)^{* *}$ & $-.02(-1.49)$ \\
\hline Level $1 R^{2}$ & .05 & .05 & .05 \\
\hline Level $2 R^{2}$ & .40 & .30 & .43 \\
\hline
\end{tabular}

Note: $\mathrm{HRM}=$ human resources management.

${ }^{\mathrm{a}}$ Grand-mean centered.

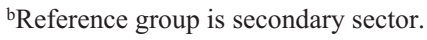

${ }^{\mathrm{c}}$ Group-mean centered.

dSignificance tests for parameters of variables with unidirectional hypotheses are one tailed.

$* p<.05$.

$* * p<.01$.

$* * * p<.001$.

I-PFP, we used PROCESS to test the serial multiple mediation (at country level) from masculinity sequentially via labor regulation and union influence. We found a significant total effect $(.02, p=.003)$ of masculinity on I-PFP and significant total indirect effect $(.01, p=$ .048) but a nonsignificant direct effect, suggesting the effect of masculinity on I-PFP to be entirely mediated by paths via labor regulation and union influence.

The results tell three very clear stories. The first is that at the country level, both culture and the institutional environment explain significant variance in the use of I-PFP. However, we note that it is only masculinity (and not individualism or uncertainty avoidance) that shows a significant association with I-PFP adoption and that its effect on I-PFP seems to be entirely mediated via employment regulation and union influence.

The second story is one of agency. The high degree of interfirm variability within countries suggests that while national institutions constitute a significant influence on firms, they do not prevent the adoption of I-PFP practices. This second, agency story finds further support when we take into account the results that suggest that the firm-level factor of HR being seen as strategically important is associated with I-PFP adoption. Hence, on the one hand, our findings indicate that cultural and institutional effects at country level influence the adoption of I-PFP. On the other, senior managers' agency counts; firms viewing HR as strategically important are more likely to adopt I-PFP. A further indication of the validity of the agency story lies in the role of foreign ownership. Regardless of country of origin, foreign-owned 
firms in general show greater propensity to adopt I-PFP than domestic firms. We note that while a number of studies have shown country-of-origin effects when, for example, comparing domestic firms with subsidiaries of U.S. MNCs (e.g., Gooderham, Nordhaug, \& Ringdal, 1998; Harzing \& Sorge, 2003), our findings suggest that such studies may have confounded country-of-origin effects with those of foreign ownership. On the evidence of our study at least, multinational firms do not necessarily seek to impose home country practices but seem to converge toward a global standard.

Third, the results provide a clear indication of the pathways through which the countrylevel structural variables affect firm behavior. We find the effect of labor regulation on I-PFP to be mediated by its effects on labor union influence, and we find the effects of culture on I-PFP to be entirely mediated by institutional configuration (labor regulation and countrylevel union influence).

\section{Discussion}

One important motivation for our study was to distinguish the role of cultural and institutional influences. Our findings suggest that around 19\% of variance in firm-level I-PFP is explained at country level, indicating that country-level effects have an important impact on firm behavior. This is of significant interest, since some have argued (Gerhart \& Fang, 2005; Wright \& van de Voorde, 2009) that culture is unlikely to explain large cross-national differences in management practices. Our findings suggest a more nuanced position: that country differences are important but do not dominate and that culture alone is insufficient to explain cross-national differences. Indeed, our study indicates that a country's institutions explain unique variance over and above the effect of culture on the use of I-PFP. Further, while culture in terms of masculinity/femininity plays some role in determining I-PFP use, this role is entirely mediated via institutional configuration (labor regulation and between-country differences in the influence of labor unions).

Our findings imply significant consequences for researchers who use culture as their exclusive measure of cross-national differences. Cultural explanations of cross-national differences have dominated the field of international management, while institutional analysis has been underused especially in relation to large cross-national studies of management practices. An important implication for international management education is that institutional explanations of cross-national diversity in management practices should be given significantly greater attention.

A second motivation for this study was to contribute to the theoretical exchanges concerning structure versus agency in organizational behavior. As indicated above, organizational analysis can be divided into theories emphasizing structure and those that stress agency. Structural theories have focused on organizational similarity and have been criticized for failing to explain variations in practice (Souitaris, Zerbinati, \& Liu, 2012). Wright and van de Voorde (2009) have suggested that prior work on cross-national variation in management practices has often overstated the impact of culture because of a failure to use multilevel methods. They argue that many studies fail to separate out country-level variance from firmlevel variance and that the former is small. However, while Wright and van de Voorde's critique is based on studies that have employed cultural theory to capture national-level effects, our findings suggest that it also has some validity for studies employing institutional theory. In all 26 countries we investigated, we find firms with a wide range of I-PFP adoption: 
Regardless of country context, there is considerable variability at the firm level in its use. Further, there is no significant association between labor regulation and within-country variability in I-PFP adoption. This is important, since our finding that legal systems influence but do not entirely constrain firms' compensation practices lends support to Oliver's (1991) argument that firms can exercise strategic agency and engage in active resistance to institutional constraints.

Our finding that structure influences but does not uniformly constrain managerial choice is given further validation in our firm-level analyses of the adoption of I-PFP. We observe that firm-level choices founded in the strategic importance managers attach to HR are significant in regard to I-PFP use, regardless of national context. Thus, firms that take the view that HRM is strategically important are significantly more likely to adopt I-PFP. Likewise, managers of firms with foreign owners are more likely to set aside local cultural and institutional influences, thereby underscoring the latitude available to managers. This suggests that firmlevel strategic choices are important in I-PFP adoption and, together with the variability in I-PFP adoption in all countries, further supports the notion that national institutions influence rather than constrain strategic choice.

While our use of a multilevel approach is a strength in that it enables us to analyze the impact of both country- and firm-level factors, including cross-level mediation, our application is somewhat narrow in terms of firm-level factors. We recommend that future studies of cross-national variation in management practice consider extending the number of antecedents of the use of I-PFP and that they examine managerial practices beyond I-PFP.

A second strength of our study is that capturing data on country-level variables from a different source to the firm-level dependent variable reduces problems of common-method variance and therefore strengthens our confidence in our results. However, at the firm level, a limitation of our study is our reliance on a single informant. Wright, Gardner, Moynihan, Park, Gerhart, and Delery (2001) have argued that single-respondent measures of management practices contain large amounts of measurement error. In our study, this problem is mitigated in three ways. First, as Wright et al. recommend, data collection focused on using the most knowledgeable raters (in this case, the most senior HR manager). Second, again as recommended by Wright et al., considerable attention was paid to constructing questions that would fall within the knowledge of respondents to answer; collaboration between researchers located in each country of data collection ensured all questions were relevant and comprehensible in the local context. Finally, as Arthur and Boyles (2007) note, while it is clear that single informants are problematic, where the constructs being measured are essentially individual or team level, where, as with compensation systems, components are clearly objective and easily observed at the firm level, a single informant may be more appropriate. A single expert informant will indeed be preferable to multiple less knowledgeable informants. We further suggest that senior HR managers are well placed to give accurate testimony as to HR department involvement in strategic decisions, the use or not of I-PFP in the firm, labor union influence, and firm ownership.

We see two practical implications of our findings. The first of these addresses managers and also has consequences for management education. Our findings indicate that firms have more latitude to engage in choosing their management practices than institutional and cultural theories suggest. In their adoption of I-PFP, we find that national context influences rather than constrains. Further, we observe that within the same context, foreign-owned firms are 
more likely to implement I-PFP than are their domestically owned counterparts. Thus, it would appear that national context has less influence on foreign-owned firms. Additionally, we observe that regardless of both national context and ownership, there are firms that have developed a view of the strategic importance of HRM that has led them to implement I-PFP. In short, our advice to managers is that they should carefully analyze what part of their practices is simply a product of a "taken-for-granted" mind-set (Brown \& Eisenhardt, 1998), since they may have wider choice sets in management practice adoption than they habitually notice.

The second practical implication concerns national-level policy makers within the area of labor regulation. Campbell (2007) argues that state regulations do not necessarily directly influence corporate behavior, but rather, it is the capacity of the state to monitor corporate behavior and enforce regulations when necessary. However, Campbell (2007: 955) further argues that we should not assume that states can do this in isolation; state regulations "turn in part on the capacity of external actors, such as ... unions ... and other stakeholders, to participate in and monitor regulatory processes." Our cross-level findings indicate that labor union influence mediates the effect of labor regulation on the propensity of firms to use I-PFP. Thus, labor unions appear to exercise a "watchdog" role on behalf of a country's labor regulation. We infer from this that when national policy makers consider developing labor regulation, they will have to reflect on not only whether the state has the capacity to influence firm behavior but also whether there are other politically empowered national-level mediating bodies that can contribute to overseeing regulations (Acemoglu \& Robinson, 2012). While labor unions are one such possible body, it is conceivable that other bodies, such as employers' associations, could play a comparable role. However, without any such body or bodies, our results suggest that forms of labor regulation that rest solely on state regulation initiatives will have more limited influence than in contexts where stakeholder monitoring is present.

\section{References}

Acemoglu, D., \& Robinson, J. A. 2012. Why nations fail: the origins of power, prosperity and poverty. New York: Crown Business.

Alesina, A., Algan, Y., Cahuc, P., \& Giuliano, P. 2015. Family values and the regulation of labor. Journal of the European Economic Association, 13: 599-630.

Alesina, A., \& Giuliano, P. 2013. Culture and institutions. Cambridge, MA: National Bureau of Economic Research.

Allison, P. D. 2001. Missing data. Thousand Oaks, CA: Sage.

Arthur, J. B., \& Boyles, T. 2007. Developing the human resource system structure: A levels-based framework for strategic HRM research. Human Resource Management Review, 17: 77-92.

Baron, R. M., \& Kenny, D. A. 1986. The moderator-mediator variable distinction in social psychological research: Conceptual, strategic and statistical considerations. Journal of Personality and Social Psychology, 51: 11731182.

Battilana, J., Leca, B., \& Boxenbaum, E. 2009. How actors change institutions: Towards a theory of institutional entrepreneurship. Academy of Management Annals, 3: 65-107.

Beck, N., Kabst, R., \& Walgenbach, P. 2009. The cultural dependence of vocational training. Journal of International Business Studies, 40: 1374-1395.

Björkman, I., Budhwar, P., Smale, A., \& Sumelius, J. 2008. Human resource management in foreign-owned subsidiaries: China versus India. International Journal of Human Resource Management, 19: 964-978.

Bormann, S. 2007. Angriff auf die Mitbestimmung. Unternehmensstrategien gegen Betriebsräte-der Fall Schlecker. Berlin, Germany: Sigma.

Botero, J., Djankov, S., La Porta, R., Lopez-de-Silanes, S., \& Shleifer, A. 2004. The regulation of labor. Quarterly Journal of Economics, 119: 1339-1382. 
Brewster, C., Hegewisch, A., Mayne, L., \& Tregaskis, O. 1994. Methodology of the Price Waterhouse Cranfield project. In C. Brewster \& A. Hegewisch (Eds.), Policy and practice in European human resource management: 230-245. London, UK: Routledge.

Brewster, C., Tregaskis, O., Hegewisch, A., \& Mayne, L. 1996. Comparative research in human resource management: A review and an example. International Journal of Human Resource Management, 7: 585-604.

Brown, S. L., \& Eisenhardt, K. M. 1998. Competing on the edge: Strategy as structured chaos. Cambridge, MA: Harvard Business School Press.

Campbell, J. L. 2007. Why would corporations behave in socially responsible ways? An institutional theory of corporate social responsibility. Academy of Management Review, 32: 946-967.

Crossland, C., \& Hambrick, D. C. 2011. Differences in managerial discretion across countries: How national-level institutions affect the degree to which CEOs matter. Strategic Management Journal, 32: 797-819.

Croucher, R., Gooderham, P., \& Parry, E. 2006. The influences on direct communication in British and Danish firms: Country, "strategic HRM," or unionization? European Journal of Industrial Relations, 12: 267-286.

Deakin, S., Lele, P., \& Siems, M. 2007. The evolution of labor law: Calibrating and comparing regulatory regimes. International Labor Review, 146: 133-162.

DiMaggio, P. J., \& Powell, W. W. 1983. The iron cage revisited: Institutional isomorphism and collective rationality in organizational fields. American Sociological Review, 48: 147-160.

DiMaggio, P. J., \& Powell, W. W. 1991. Introduction. In W. W. Powell \& P. J. DiMaggio (Eds.), The new institutionalism in organizational analysis: 1-38. Chicago: University of Chicago Press.

Fenton-O'Creevy, M., Gooderham, P. N., \& Nordhaug, O. 2008. Human resource management in US subsidiaries in Europe and Australia: Centralization or autonomy? Journal of International Business Studies, 39: 151-166.

Fenton-O'Creevy, M., \& Wood, S. 2007. Diffusion of human resource management systems in UK headquartered multinational enterprises: Integrating institutional and strategic choice explanations. European Journal of International Management, 1: 329-349.

Geppert, M., Matten, D., \& Williams, K. 2002. Global change management approaches in MNCs and distinct national trajectories: Britain and Germany compared. In M. Geppert, D. Matten, \& K. Williams (Eds.), Challenges for human resource management in a global context: 42-67. Basingstoke, UK: Palgrave.

Gerhart, B., \& Fang, M. 2005. National culture and human resource management: Assumptions and evidence. International Journal of Human Resource Management, 16: 971 - 986.

Gerhart, B., Rynes, S. L., \& Fulmer, I. S. 2009. Pay and performance: Individuals, groups and executives. Academy of Management Annals, 3: 251-315.

Gooderham, P. N., Nordhaug, O., \& Ringdal, K. 1998. When in Rome do they do as the Romans? HRM practices of US subsidiaries in Europe. Management International Review, 38(Special Issue 2): 47-64.

Gooderham, P. N., Nordhaug, O., \& Ringdal, K. 1999. Institutional and rational determinants of organizational practices: Human resource management in European firms. Administrative Science Quarterly, 44: 507-531.

Gooderham, P. N., Nordhaug, O., \& Ringdal, K. 2006. National embeddedness and HRM in U.S. subsidiaries in Europe and Australia. Human Relations, 59: 1491-1513.

Hall, P. A., \& Gingerich, D. W. 2004. Varieties of capitalism and institutional complementarities in the macroeconomy. MPIfG discussion paper 04/5. Berlin: Max Planck Institut für Gesellschaftsforschung.

Hall, P. A., \& Soskice, D. (Eds.). 2001. Varieties of capitalism: The institutional basis of competitive advantage. Oxford, UK: Oxford University Press.

Hall, P. A., \& Thelen, K. 2009. Institutional change in varieties of capitalism. Socio-Economic Review, 7: 7-34.

Harzing, A. W., \& Sorge, A. 2003. The relative impact of country-of-origin and universal contingencies on internationalization strategies and corporate control in multinational enterprises: World-wide and European perspectives. Organization Studies, 24: 187-214.

Hayes, A. F. 2008. Introduction to mediation, moderation, and conditional process analysis: A regression-based approach. New York: Guilford Press.

Heugens, P. P., \& Lander, M. W. 2009. Structure! Agency! (and other quarrels): A meta-analysis of institutional theories of organization. Academy of Management Journal, 52: 61-85.

Hofstede Center. 2014. Dimension data matrix. Retrieved March 26, 2014, from http://www.geerthofstede.nl/ dimension-data-matrix.

Hofstede, G. 1980a. Culture's consequences: International differences in work-related values. Thousand Oaks, CA: Sage. 
Hofstede, G. 1980b. Motivation, leadership and organization: Do American theories apply abroad? Organizational Dynamics, Summer: 42-63.

Hofstede, G. 1983. The cultural relativity of organizational practices and theories. Journal of International Business Studies, 14: 75-89.

Hofstede, G. 1993. Cultural constraints in management theories. Academy of Management Executive, 71: 81-94.

Hofstede, G., Hofstede, G. J., \& Minkov, M. 2010. Cultures and organizations: Software of the mind (rev. 3rd ed.). New York: McGraw-Hill.

House, R. J., Hanges, P. J., Javidan, M., Dorfman, P. W., \& Gupta, V. 2004. Culture, leadership and organizations: The GLOBE study of 62 societies. Thousand Oaks, CA: Sage.

Hui, C. H., Triandis, H. C., \& Yee, C. 1991. Cultural differences in reward allocation: Is collectivism the explanation? British Journal of Social Psychology, 30: 145-157.

Johnson, V. 2007. What is organizational imprinting? Cultural entrepreneurship in the founding of the Paris Opera. American Journal of Sociology, 113: 97-127.

Katz, H. C. 1997. Industrial relations in the U.S. automobile industry: An illustration of increased decentralization and diversity. Economic and Labor Relations Review, 8: 192-220

Kehoe, R. R., \& Wright, P. M. 2013. The impact of high-performance human resource practices on employees' attitudes and behaviors. Journal of Management, 39: 366-391.

Kostova, T., \& Roth, K. 2002. Adoption of an organizational practice by subsidiaries of multinational corporations: Institutional and relational effects. Academy of Management Journal, 45: 215-233.

Larkin, I., Pierce, L., \& Gino, F. 2012. The psychological costs of pay-for-performance: Implications for the strategic compensation of employees. Strategic Management Journal, 33: 1194-1214.

Lazarova, M., Morley, M., \& Tyson, S. 2012. International comparative studies in HRM and performance-The CRANET data. In M. Lazarova, M. Morley, \& S. Tyson (Eds.), International human resource management, policy and practice: 1-9. Abingdon, UK: Routledge.

McGovern, P., Gratton, L., Hope-Hailey, V., Stiles, P., \& Truss, C. 1997. Human resource management on the line? Human Resource Management Journal, 7: 12-29.

Metcalf, D., Hansen, K., \& Charlwood, A. 2001. Unions and the sword of justice: Unions and pay systems, pay inequality, pay discrimination and low pay. National Institute Economic Review, 176: 61-75.

Morrison, C., Croucher, R., \& Cretu, O. 2012. Legacies, conflict and "path dependence" in the former Soviet Union. British Journal of Industrial Relations, 50: 329-351.

Nyberg, A. J., Pieper, J. R., \& Trevor, C. O. 2013. Pay-for-performance's effect on future employee performance: Integrating psychological and economic principles toward a contingency perspective. Journal of Management. Advance online publication.

Oliver, C. 1991. Strategic responses to institutional processes. Academy of Management Review, 16: 145-179.

Osterman, P. 2011. Reconsidering institutional labor economics. Industrial and Labor Relations Review, 64: 635-651.

Pache, A., \& Santos, F. 2010. When worlds collide: The internal dynamics of organizational responses to conflicting institutional demands. Academy of Management Review, 35: 455-476.

Parry, E., Stavrou, E., \& Lazarova, M. 2013. Introduction: Human resource management across time and context: Comparative research and global trends in HRM. In E. Parry, E. Stavrou, \& M. Lazarova (Eds.), Global trends in human resource management: 1-11. London, UK: Palgrave Macmillan.

Raudenbush, S., \& Bryk, A. 2002. Hierarchical linear models: Applications and data analysis methods (2nd ed.). Thousand Oaks, CA: Sage.

Sakamoto, A., Woo, H., Takei, I., \& Murase, Y. 2012. Cultural constraints on rising income inequality: A US-Japan comparison. Journal of Economic Inequality, 10: 565-581.

Sanders, W. G., \& Tuschke, A. C. 2007. The adoption of institutionally contested organizational practices: The emergence of stock option pay in Germany. Academy of Management Journal, 50: 33-56.

Schuler, R. S., \& Rogovsky, N. 1998. Understanding compensation practice variations across firms. The impact of national culture. Journal of International Business Studies, 29: 159-177.

Shaw, J. D., Gupta, N., \& Delery, J. E. 2000. Empirical organizational-level examinations of agency and collaborative predictions of performance-contingent compensation. Strategic Management Journal, 21: 611-623.

Sheehan, C. 2005. A model for HRM strategic integration. Personnel Review, 34: 192-209.

Sijtsma, K., \& Molenaar, I. W. 2002. Introduction to nonparametric item response theory. London, UK: Sage.

Smith, P. B., Dugan, S., \& Trompenaars, F. 1996. National culture and the values of organizational employees: A dimensional analysis across 43 nations. Journal of Cross-Cultural Psychology, 27: 231-64. 
Souitaris, V., Zerbinati, S., \& Liu, G. 2012. Which iron cage? Endo- and exo-isomorphism in corporate venture capital programs. Academy of Management Journal, 55: 477-505.

Sturman, M. C, Shao, L., \& Katz, J. 2012. The effect of culture on the curvilinear relationship between performance and turnover. Journal of Applied Psychology, 97: 46-62.

Taylor, S., Beechler, S., \& Napier, N. 1996. Toward an integrative model of strategic international human resource management. Academy of Management Review, 21: 959-985.

Tichy, N. M., Fombrun, C. J., \& Devanna, M. A. 1984. The organizational context of strategic human resource management. In C. J. Fombrun, N. M. Tichy, \& M. A. Devanna (Eds.), Strategic human resource management: 403-419. New York: Wiley.

Trevor, C. O., Gerhart, B., \& Boudreau, J. W. 1997. Voluntary turnover and job performance: Curvilinearity and the moderating influences of salary growth and promotions. Journal of Applied Psychology, 82: 44-61.

Tsui, A. S., Nifadkar, S. S., \& Ou, A. Y. 2007. Cross-national, cross-cultural organizational behavior research: Advances, gaps and recommendations. Journal of Management, 33: 426-478.

United Nations Conference on Trade and Development. 2015. Foreign direct investment indicators. Geneva, Switzerland: Author.

van Essen, M., Heugens, P. P., Otten, J., \& van Oosterhout, J. H. 2012. An institution-based view of executive compensation: A multilevel meta-analytic test. Journal of International Business Studies, 43: 396-423.

Weinstein, M., \& Kochan, T. 1995. The limits of diffusion: Recent developments in industrial relations and human resource practices in the United States. In R. Locke, T. Kochan, \& M. Piore (Eds.), Employment relations in a changing world economy: 1-32. Cambridge, MA: MIT Press.

World Bank. 2015. GDP (current US\$). World Development Indicators: online database. Retrieved July 30, 2015 , from http://data.worldbank.org/indicator/NY.GDP.MKTP.CD.

Wright, P. M., Gardner, T. M., Moynihan, L. M., Park, H. J., Gerhart, B., \& Delery, J. E. 2001. Measurement error in research on human resources and firm performance: Additional data and suggestions for future research. Personnel Psychology, 54: 875-901.

Wright, P. M., \& van de Voorde, K. 2009. Multilevel issues in IHRM: Mean differences, explained variance, and moderated relationships. In P. Sparrow (Ed.), Handbook of international human resource management: Integrating people, process, and context: 29-40. Chichester, UK: Wiley.

$\mathrm{Xu}$, D., \& Shenkar, O. 2002. Institutional distance and the multinational enterprise. Academy of Management Review, 27: 608-618.

Young, S. L., \& Makhija, M. V. 2014. Firms' corporate social responsibility behavior: An integration of institutional and profit maximization approaches. Journal of International Business Studies, 45: 670-698.

Zhang, Z., Zyphur, M. J., \& Preacher, K. J. 2009. Testing multilevel mediation using hierarchical linear models problems and solutions. Organizational Research Methods, 12: 695-719. 